-Review

\title{
Oxidative stress in Alzheimer's disease
}

\author{
Zhichun Chen ${ }^{1,2}$, Chunjiu Zhong ${ }^{1,2}$ \\ ${ }^{1}$ Department of Neurology, Zhongshan Hospital; The State Key Laboratory of Medical Neurobiology, Fudan University, \\ Shanghai 200032, China \\ ${ }^{2}$ The Institutes of Brain Science, Fudan University, Shanghai 200032, China \\ Corresponding author: Chunjiu Zhong. E-mail: zhongcj@163.com
}

(C) Shanghai Institutes for Biological Sciences, CAS and Springer-Verlag Berlin Heidelberg 2014

Oxidative stress plays a significant role in the pathogenesis of Alzheimer's disease (AD), a devastating disease of the elderly. The brain is more vulnerable than other organs to oxidative stress, and most of the components of neurons (lipids, proteins, and nucleic acids) can be oxidized in AD due to mitochondrial dysfunction, increased metal levels, inflammation, and $\beta$-amyloid $(A \beta)$ peptides. Oxidative stress participates in the development of $A D$ by promoting $A \beta$ deposition, tau hyperphosphorylation, and the subsequent loss of synapses and neurons. The relationship between oxidative stress and AD suggests that oxidative stress is an essential part of the pathological process, and antioxidants may be useful for AD treatment.

Keywords: Alzheimer's disease; oxidative stress; $\beta$-amyloid; tau; metals; antioxidants

\section{Introduction}

The human brain, although it constitutes only $2 \%$ of the body weight, consumes $\sim 20 \%$ of the oxygen supplied by the respiratory system ${ }^{[1]}$. The high energy-consumption of the brain means that it is more susceptible to oxidative stress than any other organ. As the basic functional unit of the brain, the neuron is particularly vulnerable to oxidative damage because it has a higher metabolic rate than other cells $^{[2]}$. The oxidation of lipids, proteins, and nucleic acids in neurons is a common pathological feature of Alzheimer's disease $(A D)^{[3]}$. Neurons contain a large amount of polyunsaturated fatty acids (PUFAs) that can interact with reactive oxygen species (ROS), leading to a selfpropagating cascade of lipid peroxidation and molecular destruction $^{[4]}$. Furthermore, neurons contain low levels of glutathione, an essential antioxidant for eliminating free radicals ${ }^{[5]}$. Therefore, neurons are highly susceptible to oxidative stress.

An increased oxidative burden has been reported in the brains of non-demented elderly and/or sporadic $A D$ patients $^{[6,7]}$. Increased levels of oxidative stress biomarkers in the blood reflect such stress in the brain ${ }^{[8,9]}$. Currently, many blood markers of oxidative stress have been identified in $A D$ patients or related animal models, including protein carbonyls and 3-nitrotyrosine ${ }^{[10,11]}$, 8-hydroxydeoxyguanosine (8-OHdG), 8-hydroxyguanosine (8-OHG), malondialdehyde (MDA $)^{[12]}$, 4-hydroxynonenal (4-HNE), and F2-isoprostanes (F2-IsoPs) ${ }^{[13-16]}$. Apart from the intracellular accumulation of free radicals, changes in the activities or expressions of antioxidant enzymes, such as superoxide dismutase (SOD) and catalase, have also been described in both the central nervous system and peripheral tissues of $A D$ patients ${ }^{[14,17]}$. Thus, oxidative stress is an important pathological feature in AD.

However, how and where the oxidative stress originates in $A D$ are open questions. Research has suggested that mitochondrial dysfunction ${ }^{[12,18,19]}$, metal accumulation $^{[12,20,21]}$, hyperphosphorylated $\operatorname{tau}^{[22,23]}$, inflammation $^{[24,25]}$, and $\beta$-amyloid $(A \beta)$ accumulation $^{[12,19]}$ are the basic mechanisms underlying the induction of oxidative stress. Deficiency or destruction of components of the antioxidant system such as SOD in the mitochondria (Mn-SOD or SOD2) and cytosol (Cu-Zn-SOD or SOD1), 
glutathione peroxidases, and catalase, is also involved in the induction of oxidative stress ${ }^{[14,17,26]}$. Inactivation and deficiency of these enzymes reduce the clearance of free radicals. On the other hand, oxidative stress is an important contributor to $A \beta$ accumulation and tau hyperphosphorylation, suggesting that it plays an essential role in the pathogenesis of $A D^{[12,19,27]}$, and may be a biomarker and treatment target for $A D^{[27-29]}$.

\section{Oxidative Stress Is a Common Pathological Feature in $A D$}

\section{Lipid Oxidation}

The brain is rich in phospholipids, which are critical to the processes of neurotransmission, and the basis of neuronal interactions and cognition. Brain phospholipids contain a high proportion of PUFAs, especially docosahexaenoic acid and arachidonic acid. It has been found that as free radical production increases, the PUFAs contents in the brain gradually decline ${ }^{[30,31]}$. In addition, the lipid hydroperoxides are particularly unstable and can automatically decompose into various products, including MDA, 4-HNE, ketones, epoxides, and hydrocarbons in the presence of iron ${ }^{[30]}$. Several studies have confirmed an increase of MDA and 4-HNE levels in the brains of patients with $A D$ and mild cognitive impairment $(\mathrm{MCl})^{[13,32,33]}$. Isoprostane production is another outcome of lipid peroxidation. F2-IsoPs are produced from arachidonic acid via esterification. In AD, increased levels of F2-IsoPs and F4-IsoPs have been detected in the cerebrospinal fluid (CSF) ${ }^{[15,34]}$. Interestingly, the level of F2-IsoPs in the ventricular fluid is negatively correlated with brain weight ${ }^{[35]}$. Another study also found that the amount of F2-IsoPs is increased in $\mathrm{MCl}$ patients ${ }^{[36]}$.

\section{Protein Oxidation}

Increased level of protein carbonyl, a marker of oxidative damage to proteins, has been demonstrated in the $A D$ brain $^{[33]}$. Reactions of various reactive oxygen and nitrogen species with tyrosine result in the production of 3-nitrotyrosine and dityrosine. In particular, the 3-nitrotyrosine residue concentration in the CSF is negatively correlated with the Mini-Mental State Examination score ${ }^{[37]}$. Furthermore, protein nitration is an early event in the pathogenesis of AD. For example, the levels of total protein nitration in the inferior parietal lobule and in the hippocampus from patients with $\mathrm{MCl}$ are much higher than those in healthy control subjects ${ }^{[38]}$.

\section{Nucleic Acid Oxidation}

DNA oxidation can lead to the formation of $8-\mathrm{OHdG}$. The 8-OHdG level in mitochondrial DNA isolated from the parietal cortex of AD patients is significantly increased (three times) as compared to control subjects ${ }^{[39]}$. Oxidative modification to RNA is also increased in the AD brain ${ }^{[40]}$. Interestingly, 8-OHG appears to precede all the typical hallmarks of $A D$, such as neurofibrillary tangles (NFTs) and $A \beta$ plaques, and specifically occurs decades before $A \beta$ aggregation in $A D$ patients. Another way to measure DNA oxidation is to determine DNA strand breakage. It has been reported that the level of DNA breakage in the cerebral cortex of $A D$ patients is twice that in controls ${ }^{[41]}$.

All of these products of the oxidation of lipids, proteins, and nucleic acids have been considered as blood biomarkers for early $A D$ diagnosis ${ }^{[30]}$. Their efficacy as early biomarkers of $A D$ needs further study.

\section{Oxidative Stress Is Induced by Multiple Mechanisms}

\section{Mitochondrial Dysfunction}

The mitochondria are much more susceptible to oxidative stress as the site of the electron transport chain for adenosine triphosphate (ATP) production and the main source of $\operatorname{ROS}^{[42,43]}$. Mitochondrial dysfunction and subsequent metabolic abnormality have been found in hippocampal neurons of AD patients ${ }^{[44,45]}$. Deficiency of cytochrome oxidase, a key electron transport enzyme, is responsible for the increase of ROS production and the reduction in energy stores in $A D^{[46]}$. Mn-SOD, an antioxidant enzyme that protects mitochondria from oxidative stress, is inactivated in APP/PS1 transgenic mice, and Mn-SOD inactivation further promotes mitochondrial dysfunction, oxidative stress, and apoptosis ${ }^{[47]}$. All these findings indicate that ROS production is intimately associated with mitochondrial dysfunction, especially abnormality of the electron transport chain.

$A \beta$ is the most important culprit for mitochondrial dysfunction, and thus contributes to the ROS production in $A D$ (Fig.1). Accumulating evidence shows that $A \beta$ disturbs the electron transport chain by reducing the activities of key enzymes ${ }^{[48]}$ and disrupting mitochondrial dynamics ${ }^{[19,49]}$. These pathological changes are involved in oxidative 


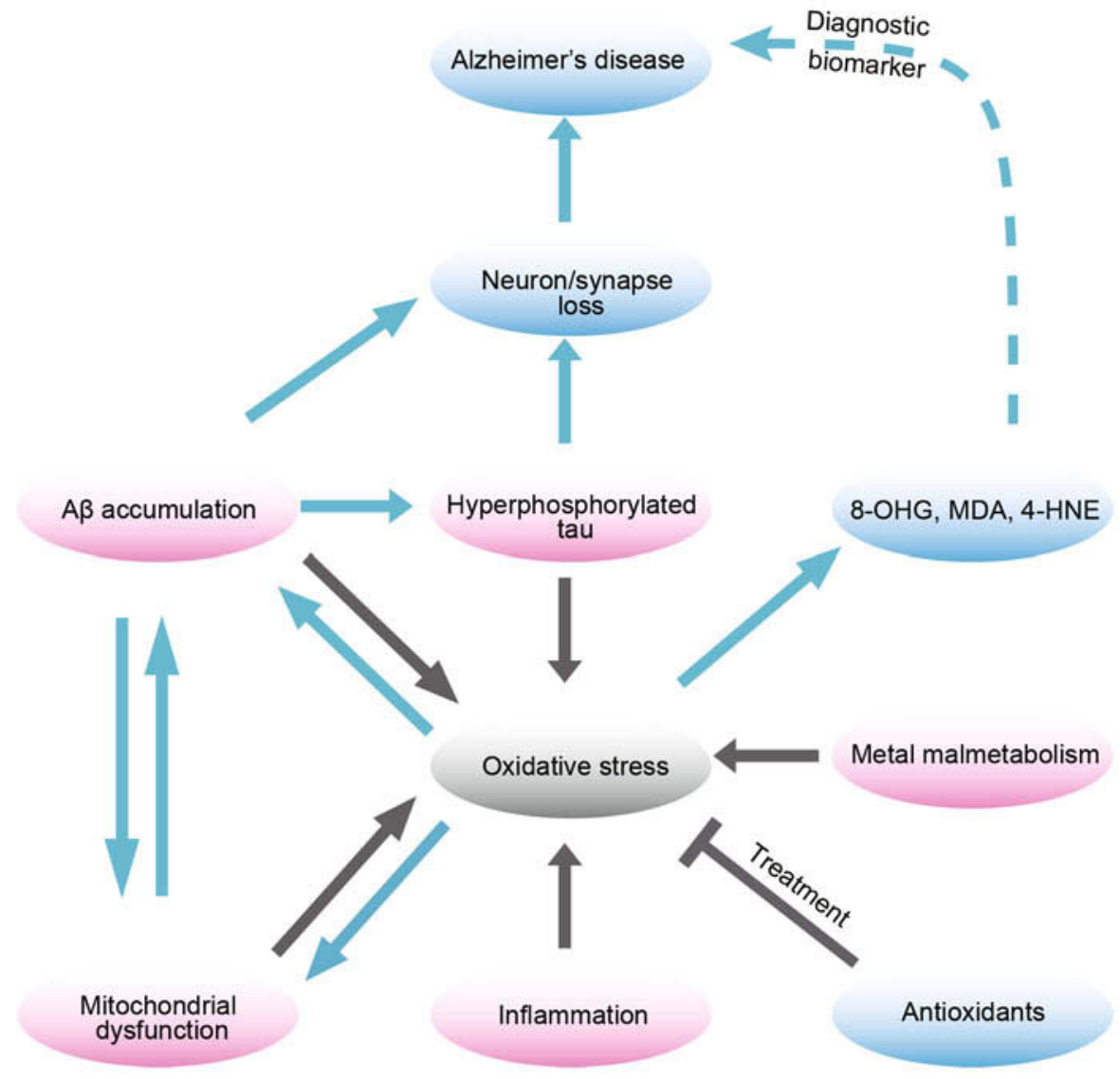

Fig. 1. Oxidative stress in Alzheimer's disease. The schematic shows how oxidative stress can be induced by mitochondrial dysfunction, metal malmetabolism, inflammation, hyperphosphorylated tau and $A \beta$ accumulation in $A D$. Besides, the products of oxidative stress in the brain, such as 8-OHG, MDA, and 4-HNE may be used for AD diagnosis. Finally, considering the essential role of oxidative stress in $A D$, antioxidants may be used for treatment.

stress $^{[12]}$, dysfunction of mitochondrial axonal transport ${ }^{[50]}$, and mitochondrial DNA (mtDNA) mutation ${ }^{[19]}$. Soluble $A \beta$ is correlated with increased hydrogen peroxide levels and decreased activity of cytochrome $c$ oxidase in Tg2576 mice, prior to the appearance of $A \beta$ plaques $^{[51]}$. In isolated mitochondria, $A \beta$ treatment causes oxidative injury to the mitochondrial membrane, impairs lipid polarity and protein mobility, and inhibits key enzymes of the respiratory chain. Consequently, mitochondrial membrane permeability and cytochrome $c$ release are increased, and apoptosis is evoked ${ }^{[48,52]}$. Hirai et al. (2001) also reported that intracellular $A \beta$ interferes with oxidative phosphorylation and ROS production within mitochondria, and this is related to the decreases in mitochondrial membrane potential, complex IV (cytochrome $c$ oxidase) activity, and ATP production $^{[44]}$. Consistently, various $A D$ transgenic mouse models carrying mutants of amyloid precursor protein (APP) and presellien-1 (PS-1) exhibit increased hydrogen peroxide and nitric oxide production as well as elevated oxidative modification of proteins and lipids correlated with ageassociated $A \beta$ accumulation, indicating that $A \beta$ promotes oxidative stress ${ }^{[53-55]}$. $A \beta$ also binds to $A \beta$-binding alcohol dehydrogenase (ABAD), a member of the short-chain dehydrogenase reductase family in mitochondria, to induce apoptosis and ROS production in neurons, which can be prevented by ABAD inhibitors ${ }^{[56]}$. Besides, mitochondria are dynamic organelles that constantly undergo fission (splitting) and fusion (combining). Abnormal mitochondrial dynamics is associated with the production of free radicals. Particularly, excessive mitochondrial fragmentation results 
in increased ROS production. For example, mitochondrial fragmentation accounts for increased high-glucoseinduced respiration and ROS overproduction, which can be prevented by inhibition of mitochondrial fission ${ }^{[57]}$. Fission of mitochondria in $A D$ seems to be more prevalent than fusion $^{[19,58]}$. The level of dynamin-related protein 1 (Drp1), a regulator of mitochondrial fission, is reduced in sporadic $A D$ fibroblasts, and it may be correlated with exposure to $A \beta^{[59]}$. Uncoupling proteins (UCPs) are a family of mitochondrial anion carrier proteins that are anchored to the inner membrane and have diverse physiological functions ${ }^{[60]}$. UCP2 and UCP3 are activated in response to oxidative stress to protect mitochondria ${ }^{[61]}$. However, this protective effect is disrupted in cells overexpressing APP or mutant $A P P^{[62]}$, which further leads to progressive mitochondrial dysfunction and ROS production.

Mutations in mtDNA play a significant role in mitochondrial dysfunction in AD. Studies have revealed a causal relationship between mtDNA mutations and ROS production in the affected tissues of patients with mitochondrial diseases, when the mutation load of mtDNA reaches a threshold ${ }^{[63,64]}$. For example, skin fibroblasts isolated from patients with myoclonic epilepsy with red ragged fibers (MERRF) show enhancement of intracellular hydrogen peroxide levels and oxidative damage, and an imbalance of gene expression of antioxidant enzymes ${ }^{[65]}$. Similar phenomena have also been found in patients with mitochondrial encephalomyopathy and lactic acidosis with stroke-like episodes (MELAS) ${ }^{[66]}$ and Leber's hereditary optic neuropathy (LHON) $)^{[67]}$.

\section{Metal Accumulation}

In the hippocampus, amygdala, and other brain regions with severe histopathological changes in AD patients, abnormal levels of copper, zinc, and iron have been reported ${ }^{[68]}$. Metals can interact with $A \beta$ to induce oxidative stress (Fig.1). By binding to copper or iron, $A \beta$ produces ROS by redox activity, and metal chelators reduce $A \beta$ levels and prevent its aggregation by attenuating the metal overload ${ }^{[21,69,70]}$. $\mathrm{A} \beta$ binds $\mathrm{Cu}^{2+}$ with high affinity, forming a cuproenzyme-like complex ${ }^{[71]}$. During this process, the electron is transferred from $\mathrm{A} \beta$ to $\mathrm{Cu}^{2+}$, converting $\mathrm{Cu}^{2+}$ to $\mathrm{Cu}^{+}$and forming the $\mathrm{A} \beta$ radical $\left(A \beta^{+*}\right)^{[72]}$. In addition, $\mathrm{Cu}^{+}$can donate two electrons to oxygen, generating $\mathrm{H}_{2} \mathrm{O}_{2}{ }^{[72,73]}$, and further producing hydroxyl radicals (Fenton-type reaction) ${ }^{[74]}$. Iron accumulation is also present in cells associated with neuritic plaques in $A D^{[75]}$, which results in the increase of oxidative stress. However, it has been shown that hemochromatosis mutations are associated with increased oxidative stress and progression of disease pathology ${ }^{[76]}$. Similar to the copper-A $\beta$ interaction, the binding of iron to $A \beta$ results in a reduction of $\mathrm{Fe}^{3+}$ to $\mathrm{Fe}^{2+}$ and the generation of $\mathrm{H}_{2} \mathrm{O}_{2}^{[77]}$. In SH-SY5Y cells overexpressing the Swedish mutant form of human APP, the intracellular iron is significantly elevated along with increased oxidative stress ${ }^{[78]}$. These findings show that ROS are produced by the interactions between $A \beta$ and metals. In addition, aluminum is associated with $A D$ neurodegeneration by oxidative stress and inflammation ${ }^{[3]}$. As one of the key components in amyloid plaques and cerebrovascular amyloidosis, zinc is also considered to be correlated with $A D$. Evidence from triple-transgenic mice demonstrated that APP, PS1, and PS2 mutations produce ROS to mobilize zinc from extracellular metallothionein ${ }^{[79]}$, which may be involved in $A \beta$ accumulation ${ }^{[80]}$.

\section{Hyperphosphorylated Tau}

Hyperphosphorylated tau protein, the major component of NFTs and a hallmark of AD, is significantly correlated with the neurodegeneration and cognitive decline ${ }^{[81]}$. Interestingly, neurons with NFTs have significantly lower 8-OHG levels despite obvious oxidative damage. This implies that tau phosphorylation and NFT formation may play a role in protecting neurons from oxidative insult ${ }^{[82]}$ (Fig.1). However, most studies indicate that tau is involved in the neurodegeneration associated with oxidative stress in AD. In a Drosophila model of human tauopathy (tau $\mathrm{R} 406 \mathrm{~W})$, a reduction in the gene dosage of thioredoxin reductase or mitochondrial SOD2 promotes tau-induced neurodegenerative histological abnormalities and neuronal apoptosis $^{[23]}$. On the contrary, overexpression of these antioxidant enzymes or treatment with vitamin $\mathrm{E}$ decreases the tau-induced neuronal death ${ }^{[22]}$. In addition, cortical neurons expressing truncated tau show increased levels of ROS, and antioxidants such as vitamin C eliminate this alteration ${ }^{[83]}$. A relationship between oxidative stress and tau pathology has also been demonstrated in P301S and P301L transgenic mice. The functional analysis of proteomics finds mitochondrial dysfunction together with reduced $\mathrm{NADH}$-ubiquinone oxidoreductase activity impairs mitochondrial oxidative phosphorylation and ATP synthesis ${ }^{[84-86]}$. Accordingly, coenzyme Q10 (CoQ10), an antioxidant and key component of the electron transport 
chain, significantly enhances complex I activity and reduces lipid peroxidation, and consequently, significantly improves survival and the behavioral deficits in P301S mice ${ }^{[87]}$.

\section{Inflammation}

Inflammation also participates in the production of ROS (Fig.1). Both microglia and astrocytes release proinflammatory mediators such as cytokines, chemokines, ROS, and complement proteins ${ }^{[8]} . A \beta$ attracts and activates microglia, leading to their clustering around $A \beta$ deposits in the brain. Microglia also express scavenger receptors to interact with $A \beta$, and cause ROS secretion and cell immobilization ${ }^{[89]}$. Astrocytes are also activated by $A \beta$, and hence produce chemokines, cytokines, and ROS that may result in neuronal damage ${ }^{[90,91]}$.

\section{Oxidative Stress Is an Important Contributor to the Pathology of Alzheimer's Disease}

Studies have found that $A \beta$ at physiological levels plays a self-protective role in the neuronal response to oxidative stress. Picomolar or low nanomolar levels of $A \beta$ are neurotrophic or neuroprotective ${ }^{[92]}$, efficiently suppress the auto-oxidation of lipoproteins in the CSF and plasma ${ }^{[93]}$, and dramatically increase hippocampal long-term potentiation ${ }^{[94]}$, whereas high nanomolar concentrations induce the wellestablished neurotoxicity. Low concentrations of $A \beta$ are not detrimental until their accumulation reaches a threshold level. However, neuronal oxidative damage is more pronounced in $A D$ patients with less $A \beta$ deposition or with a shorter disease duration ${ }^{[95]}$. There is an inverse relationship between the degree of oxidative damage of nucleic acids in neurons and the amounts of intraneuronal $A \beta_{42}$ in the hippocampus of the AD brain ${ }^{[96]}$. How can this contradiction be interpreted? As discussed above, ROS can be produced by disruption of oxidative phosphorylation in mitochondria or through other reactions. For example, respiratory chain dysfunction can lead to the release of free radicals, including $\operatorname{ROS}^{[12,19]}$. To eliminate these free radicals, neurons may initiate mechanisms for the prevention of oxidative damage. Interestingly, some studies suggest that $A \beta$ is initially a compensation for overwhelming concentrations of $\operatorname{ROS}^{[97,98]}$. $A \beta$ has antioxidant activity and protects lipoproteins from oxidation in the CSF and plasma; and patients with Down syndrome with the most severe $A \beta$ deposition show the lowest levels of $8-\mathrm{OHG}$, while neurons lacking $A \beta$ pathology have significantly higher levels of $8-\mathrm{OHG}^{[99]}$. Thus $A \beta$ may be characterized as an environmental stress on neurons that is induced by oxidative stress, or other pathological factors.

On the other hand, when $A \beta$ accumulates to certain extent it exhibits a detrimental effect on neurons and elicits further oxidative stress ${ }^{[82]}$. Oxidative stress reduces the activity of $\alpha$-secretase and promotes the expression and activation of $\beta$ - and $\gamma$-secretases ${ }^{[100-102]}$. The oxidative stress-induced $\beta$-site APP-cleaving enzyme 1, PS1 expression, and $\gamma$-secretase activation are mediated by activation of the c-Jun N-terminal kinase pathway ${ }^{[103]}$. Furthermore, antioxidants such as EGb 761, curcumin, and green tea catechins reduce brain $A \beta$ level and the $A \beta$ plaque burden ${ }^{[12,104-106]}$. Modification of the antioxidative system by overexpressing Mn-SOD in Tg19959 APPmutated transgenic mice decreases protein oxidation and increases antioxidant defense in the brain, resulting in a reduced $A \beta$ plaque burden and restoration of memory ${ }^{[107]}$. $A \beta$ oligomerization is also increased in the Tg2576 APPoverexpressing $A D$ mouse model by deleting cytoplasmic SOD $1^{[108]}$. In sum, oxidative stress plays an important role in $A \beta$ pathology (Fig.1).

Accumulating evidence suggests that oxidative stress also contributes to tau pathology in AD. Oxidation of fatty acids accelerates the polymerization of tau, and thus serves as a possible link between oxidative stress and the development of fibrillar pathology in $A D^{[109]}$. This polymerization is hypothesized to occur via a cysteinedependent mechanism ${ }^{[110]}$. In Tg2576 AD transgenic mice, a deficiency in mitochondrial SOD2 or a reduction of cytoplasmic SOD1 induces tau phosphorylation ${ }^{[111]}$. In addition, p38 mitogen-activated protein kinase, a kinase responsible for tau phosphorylation, is activated by oxidative stress in vitro ${ }^{[112]}$. The hyperphosphorylation of tau makes it susceptible to conformational changes by the production of paired helical filaments and subsequent NFTs. However, further studies are needed to fully clarify the role of oxidative stress in tau pathology.

\section{Antioxidants as a Treatment for Alzheimer's Disease}

The antioxidants are potential therapeutics by eliminating ROS and exerting neuroprotective effects on neurons in AD 
(Fig.1). For example, CoQ10, also known as ubiquinone, reduces oxidative stress and has neuroprotective properties both in vitro and in vivo ${ }^{[113]}$; its administration to transgenic $A D$ mice also dramatically reduces the amyloid plaque burden ${ }^{[114,115]}$. Although CoQ10 has not been tested in clinic trials, its analog, idebenone, has been assessed in AD patients, and has beneficial effects on memory and attention ${ }^{[116,117]}$. However, it failed to prevent disease progression in a later large-scale study ${ }^{[118]}$. Another CoQ10 derivative, mitoquinone mesylate or mitoQ, has also been applied to prevent oxidative damage in $A D^{[119]}$. Latrepirdine (Dimebon), a nonselective antihistamine, has shown promise in vitro for preventing ROS-mediated damage in neurodegenerative diseases ${ }^{[120]}$. In a phase- 2 trial, Dimebon was found to be well-tolerated and improved cognition, activities of daily living, and overall function in $\mathrm{MCl}$ and AD patients as compared to placebo ${ }^{[121]}$. However, more recently, the phase 3 CONNECTION trial in AD patients did not reveal any beneficial effects ${ }^{[122]}$. Curcumin has also been tested in AD patients in a pilot trial with a duration of 6 months, but had no effects on cognition and levels of isoprostanes and $A \beta^{[123]}$. Acetyl-L-carnitine (ALCAR) and $\mathrm{R}$-alpha lipoic acid are also potential antioxidants for AD therapy. Particularly, ALCAR has been tested in many clinical trials ${ }^{[124-126]}$. Other drugs, including vitamin $E^{[93,127]}$, pramipexole ${ }^{[128]}$, and Szeto-Schiller peptides ${ }^{[129]}$ have also been investigated widely, but none has received convincing confirmation of efficacy. The reason for the low efficacy or failure of the clinical trials may be that the basic pathological changes, including $A \beta$ accumulation and tau hyperphosphorylation, are not efficiently changed, even when the elimination of oxidative stress seems to be realized. Besides, as $A D$ is a multi-factorial degenerative disease, combined treatment to target multiple pathological mechanisms should be explored in order to develop effective disease-modifying therapies ${ }^{[130]}$.

\section{Conclusion}

Oxidative stress is an important pathophysiological change in $A D$. It is closely correlated with amyloid pathology and tau pathology by forming vicious pathophysiological cycles, inducing mitochondrial dysfunction and promoting metal toxicity. Oxidative stress is an essential pathological marker of $A D$, but also serves as a potential treatment target.

\section{ACKNOWLEDGEMENTS}

This review was supported by National Basic Research Development Program (973 Program) of China (2011CBA00400), the National Natural Science Foundation of China (91332201), the Natural Science Foundation of Shanghai Municipality, China (13JC1401500) and fund for Medical Emerging Cutting-edge Technology in Shanghai Municipality, China (SHDC12012114).

Received date: 2013-11-15; Accepted date: 2014-01-03

\section{REFERENCES}

[1] Sokoloff L. Energetics of functional activation in neural tissues. Neurochem Res 1999, 24: 321-329.

[2] Tholey G, Ledig M. Neuronal and astrocytic plasticity: metabolic aspects. Ann Med Interne (Paris) 1990, 141 Suppl 1: 13-18.

[3] Pratico D. Oxidative stress hypothesis in Alzheimer's disease: a reappraisal. Trends Pharmacol Sci 2008, 29: 609-615.

[4] Nunomura A, Castellani RJ, Zhu X, Moreira PI, Perry G, Smith MA. Involvement of oxidative stress in Alzheimer disease. J Neuropathol Exp Neurol 2006, 65: 631-641.

[5] Pocernich C, Butterfield D. Elevation of glutathione as a therapeutic strategy in Alzheimer disease. Biochim Biophys Acta 2012, 1822(5): 625-630.

[6] Behl C, Moosmann B. Antioxidant neuroprotection in Alzheimer's disease as preventive and therapeutic approach. Free Radic Biol Med 2002, 15;33(2):182-191.

[7] Moosmann B, Behl C. Antioxidants as treatment for neurodegenerative disorders. Expert Opin Investig Drugs 2002, 11(10): 1407-1435.

[8] Torres LL, Quaglio NB, de Souza GT, Garcia RT, Dati LM, Moreira WL, et al. Peripheral oxidative stress biomarkers in mild cognitive impairment and Alzheimer's disease. J Alzheimers Dis 2011, 26: 59-68.

[9] Beal MF. Oxidative damage as an early marker of Alzheimer's disease and mild cognitive impairment. Neurobiol Aging 2005, 26: 585-586.

[10] Beal M. Oxidatively modiied proteins in aging and disease. Free Radic Biol Med 2002, 32(9): 797-803.

[11] Butterfield D, Kanski J. Brain protein oxidation in agerelated neurodegenerative disorders that are associated with aggregated proteins. Mech Ageing Dev 2001, 122(9): 945-962.

[12] Zhao $Y$, Zhao B. Oxidative stress and the pathogenesis of Alzheimer's disease. Oxid Med Cell Longev 2013, 2013: 316523.

[13] Lovell MA, Ehmann WD, Butler SM, Markesbery WR. Elevated thiobarbituric acid-reactive substances and 
antioxidant enzyme activity in the brain in Alzheimer's disease. Neurology 1995, 45: 1594-1601.

[14] Marcus DL, Thomas C, Rodriguez C, Simberkoff K, Tsai JS, Strafaci JA, et al. Increased peroxidation and reduced antioxidant enzyme activity in Alzheimer's disease. Exp Neurol 1998, 150: 40-44.

[15] Pratico D, Clark CM, Lee VM, Trojanowski JQ, Rokach J, FitzGerald GA. Increased 8,12-iso-iPF2alpha-VI in Alzheimer's disease: correlation of a noninvasive index of lipid peroxidation with disease severity. Ann Neurol 2000, 48: 809-812.

[16] Williams TI, Lynn BC, Markesbery WR, Lovell MA. Increased levels of 4-hydroxynonenal and acrolein, neurotoxic markers of lipid peroxidation, in the brain in Mild Cognitive Impairment and early Alzheimer's disease. Neurobiol Aging 2006, 27 : 1094-1099.

[17] Omar RA, Chyan YJ, Andorn AC, Poeggeler B, Robakis NK, Pappolla MA. Increased expression but reduced activity of antioxidant enzymes in Alzheimer's disease. J Alzheimers Dis 1999, 1: 139-145.

[18] Federico A, Cardaioli E, Da Pozzo P, Formichi P, Gallus GN, Radi E. Mitochondria, oxidative stress and neurodegeneration. J Neurol Sci 2012, 322: 254-262.

[19] Yan MH, Wang X, Zhu X. Mitochondrial defects and oxidative stress in Alzheimer disease and Parkinson disease. Free Radic Biol Med 2013, 62: 90-101.

[20] Ayton S, Lei P, Bush Al. Metallostasis in Alzheimer's disease. Free Radic Biol Med 2013, 62: 76-89.

[21] Greenough MA, Camakaris J, Bush Al. Metal dyshomeostasis and oxidative stress in Alzheimer's disease. Neurochem Int 2013, 62: 540-555.

[22] Dias-Santagata D, Fulga TA, Duttaroy A, Feany MB. Oxidative stress mediates tau-induced neurodegeneration in Drosophila. J Clin Invest 2007, 117: 236-245.

[23] Stamer K, Vogel R, Thies E, Mandelkow E, Mandelkow EM. Tau blocks traffic of organelles, neurofilaments, and APP vesicles in neurons and enhances oxidative stress. J Cell Biol 2002, 156: 1051-1063.

[24] Candore G, Bulati M, Caruso C, Castiglia L, ColonnaRomano G, Di Bona D, et al. Inflammation, cytokines, immune response, apolipoprotein E, cholesterol, and oxidative stress in Alzheimer disease: therapeutic implications. Rejuvenation Res 2010, 13: 301-313.

[25] Lee YJ, Han SB, Nam SY, Oh KW, Hong JT. Inflammation and Alzheimer's disease. Arch Pharm Res 2010, 33: 15391556.

[26] Ansari MA, Scheff SW. Oxidative stress in the progression of Alzheimer disease in the frontal cortex. J Neuropathol Exp Neurol 2010, 69: 155-167.

[27] Manczak M, Mao P, Calkins MJ, Cornea A, Reddy AP,
Murphy MP, et al. Mitochondria-targeted antioxidants protect against amyloid-beta toxicity in Alzheimer's disease neurons. J Alzheimers Dis 2010, 20 Suppl 2: S609-631.

[28] Mattson MP. Pathways towards and away from Alzheimer's disease. Nature 2004, 430: 631-639.

[29] Reddy $\mathrm{PH}$. Mitochondrial oxidative damage in aging and Alzheimer's disease: implications for mitochondrially targeted antioxidant therapeutics. J Biomed Biotechnol 2006, 2006: 31372.

[30] Skoumalova A, Hort J. Blood markers of oxidative stress in Alzheimer's disease. J Cell Mol Med 2012, 16: 2291-2300.

[31] Soderberg M, Edlund C, Kristensson K, Dallner G. Fatty acid composition of brain phospholipids in aging and in Alzheimer's disease. Lipids 1991, 26: 421-425.

[32] Butterfield DA, Reed T, Perluigi M, De Marco C, Coccia $\mathrm{R}$, Cini $\mathrm{C}$, et al. Elevated protein-bound levels of the lipid peroxidation product, 4-hydroxy-2-nonenal, in brain from persons with mild cognitive impairment. Neurosci Lett 2006, 397: 170-173.

[33] Keller JN, Schmitt FA, Scheff SW, Ding $Q$, Chen $Q$, Butterfield DA, et al. Evidence of increased oxidative damage in subjects with mild cognitive impairment. Neurology 2005, 64: 1152-1156.

[34] Roberts LJ, 2nd, Montine TJ, Markesbery WR, Tapper AR, Hardy P, Chemtob S, et al. Formation of isoprostane-like compounds (neuroprostanes) in vivo from docosahexaenoic acid. J Biol Chem 1998, 273: 13605-13612.

[35] Montine TJ, Markesbery WR, Morrow JD, Roberts LJ, 2nd. Cerebrospinal fluid F2-isoprostane levels are increased in Alzheimer's disease. Ann Neurol 1998, 44: 410-413.

[36] Singh M, Dang TN, Arseneault M, Ramassamy C. Role of by-products of lipid oxidation in Alzheimer's disease brain: a focus on acrolein. J Alzheimers Dis 2010, 21: 741-756.

[37] Ahmed N, Ahmed U, Thornalley PJ, Hager K, Fleischer G, Munch $G$. Protein glycation, oxidation and nitration adduct residues and free adducts of cerebrospinal fluid in Alzheimer's disease and link to cognitive impairment. J Neurochem 2005, 92: 255-263.

[38] Butterfield DA, Reed TT, Perluigi M, De Marco C, Coccia R, Keller JN, et al. Elevated levels of 3-nitrotyrosine in brain from subjects with amnestic mild cognitive impairment: implications for the role of nitration in the progression of Alzheimer's disease. Brain Res 2007, 1148: 243-248.

[39] Mecocci P, MacGarvey U, Beal MF. Oxidative damage to mitochondrial DNA is increased in Alzheimer's disease. Ann Neurol 1994, 36: 747-751.

[40] Nunomura A, Perry G, Pappolla MA, Wade R, Hirai K, Chiba $\mathrm{S}$, et al. RNA oxidation is a prominent feature of vulnerable neurons in Alzheimer's disease. J Neurosci 1999, 19: 19591964. 
[41] Mullaart E, Boerrigter ME, Ravid R, Swaab DF, Vijg J. Increased levels of DNA breaks in cerebral cortex of Alzheimer's disease patients. Neurobiol Aging 1990, 11: 169-173.

[42] Grivennikova VG, Vinogradov AD. Generation of superoxide by the mitochondrial Complex I. Biochim Biophys Acta 2006, 1757: 553-561.

[43] Tan S, Sagara Y, Liu Y, Maher P, Schubert D. The regulation of reactive oxygen species production during programmed cell death. J Cell Biol 1998, 141: 1423-1432.

[44] Hirai K, Aliev G, Nunomura A, Fujioka H, Russell RL, Atwood CS, et al. Mitochondrial abnormalities in Alzheimer's disease. J Neurosci 2001, 21: 3017-3023.

[45] Silva DF, Selfridge JE, Lu J, E L, Cardoso SM, Swerdlow RH. Mitochondrial abnormalities in Alzheimer's disease: possible targets for therapeutic intervention. Adv Pharmacol 2012, 64: 83-126.

[46] Mutisya EM, Bowling AC, Beal MF. Cortical cytochrome oxidase activity is reduced in Alzheimer's disease. J Neurochem 1994, 63: 2179-2184.

[47] Anantharaman M, Tangpong J, Keller JN, Murphy MP, Markesbery WR, Kiningham KK, et al. Beta-amyloid mediated nitration of manganese superoxide dismutase: implication for oxidative stress in a APPNLH/NLH X PS-1P264L/P264L double knock-in mouse model of Alzheimer's disease. Am J Pathol 2006, 168: 1608-1618.

[48] Casley CS, Canevari L, Land JM, Clark JB, Sharpe MA. Beta-amyloid inhibits integrated mitochondrial respiration and key enzyme activities. J Neurochem 2002, 80: 91-100.

[49] Wang X, Su B, Siedlak SL, Moreira PI, Fujioka H, Wang $\mathrm{Y}$, et al. Amyloid-beta overproduction causes abnormal mitochondrial dynamics via differential modulation of mitochondrial fission/fusion proteins. Proc Natl Acad Sci U S A 2008, 105: 19318-19323.

[50] Crouch PJ, Harding SM, White AR, Camakaris J, Bush Al, Masters CL. Mechanisms of A beta mediated neurodegeneration in Alzheimer's disease. Int J Biochem Cell Biol 2008, 40: 181-198.

[51] Manczak M, Anekonda TS, Henson E, Park BS, Quinn J, Reddy $\mathrm{PH}$. Mitochondria are a direct site of $A \beta$ accumulation in Alzheimer's disease neurons: implications for free radical generation and oxidative damage in disease progression. Hum Mol Genet 2006, 15: 1437-1449.

[52] Rodrigues CM, Sola S, Brito MA, Brondino CD, Brites D, Moura JJ. Amyloid beta-peptide disrupts mitochondrial membrane lipid and protein structure: protective role of tauroursodeoxycholate. Biochem Biophys Res Commun 2001, 281: 468-474.

[53] Apelt J, Bigl M, Wunderlich P, Schliebs R. Aging-related increase in oxidative stress correlates with developmental pattern of beta-secretase activity and beta-amyloid plaque formation in transgenic Tg2576 mice with Alzheimer-like pathology. Int J Dev Neurosci 2004, 22: 475-484.

[54] Manczak M, Anekonda TS, Henson E, Park BS, Quinn $\mathrm{J}$, Reddy $\mathrm{PH}$. Mitochondria are a direct site of $\mathrm{A}$ beta accumulation in Alzheimer's disease neurons: implications for free radical generation and oxidative damage in disease progression. Hum Mol Genet 2006, 15: 1437-1449.

[55] Matsuoka Y, Picciano M, La Francois J, Duff K. Fibrillar betaamyloid evokes oxidative damage in a transgenic mouse model of Alzheimer's disease. Neuroscience 2001, 104: 609-613.

[56] Takuma K, Yao J, Huang J, Xu H, Chen X, Luddy J, et al. $A B A D$ enhances Abeta-induced cell stress via mitochondrial dysfunction. FASEB J 2005, 19: 597-598.

[57] Yu T, Robotham JL, Yoon Y. Increased production of reactive oxygen species in hyperglycemic conditions requires dynamic change of mitochondrial morphology. Proc Natl Acad Sci U S A 2006, 103: 2653-2658.

[58] Bonda DJ, Wang X, Perry G, Smith MA, Zhu X. Mitochondrial dynamics in Alzheimer's disease: opportunities for future treatment strategies. Drugs Aging 2010, 27: 181-192.

[59] Wang X, Su B, Fujioka H, Zhu X. Dynamin-like protein 1 reduction underlies mitochondrial morphology and distribution abnormalities in fibroblasts from sporadic Alzheimer's disease patients. Am J Pathol 2008, 173: 470-482.

[60] Baldeiras I, Santana I, Proenca MT, Garrucho MH, Pascoal $\mathrm{R}$, Rodrigues $\mathrm{A}$, et al. Oxidative damage and progression to Alzheimer's disease in patients with mild cognitive impairment. J Alzheimers Dis 2010, 21: 1165-1177.

[61] Echtay KS. Mitochondrial uncoupling proteins--what is their physiological role? Free Radic Biol Med 2007, 43: 13511371.

[62] Wu Z, Zhang J, Zhao B. Superoxide anion regulates the mitochondrial free $\mathrm{Ca}^{2+}$ through uncoupling proteins. Antioxid Redox Signal 2009, 11: 1805-1818.

[63] Piccolo G, Banfi P, Azan G, Rizzuto R, Bisson R, Sandona D, et al. Biological markers of oxidative stress in mitochondrial myopathies with progressive external ophthalmoplegia. J Neurol Sci 1991, 105: 57-60.

[64] Smits P, Mattijssen S, Morava E, van den Brand M, van den Brandt F, Wijburg F, et al. Functional consequences of mitochondrial tRNA Trp and tRNA Arg mutations causing combined OXPHOS defects. Eur J Hum Genet 2010, 18: 324-329.

[65] Wu SB, Ma YS, Wu YT, Chen YC, Wei YH. Mitochondrial DNA mutation-elicited oxidative stress, oxidative damage, and altered gene expression in cultured cells of patients with MERRF syndrome. Mol Neurobiol 2010, 41: 256-266.

[66] Ikawa M, Arakawa K, Hamano T, Nagata M, Nakamoto 
$\mathrm{Y}$, Kuriyama $\mathrm{M}$, et al. Evaluation of systemic redox states in patients carrying the MELAS A3243G mutation in mitochondrial DNA. Eur Neurol 2012, 67: 232-237.

[67] Wong A, Cavelier L, Collins-Schramm HE, Seldin MF, McGrogan M, Savontaus M-L, et al. Differentiation-specific effects of LHON mutations introduced into neuronal NT2 cells. Hum Mol Genet 2002, 11: 431-438.

[68] Deibel MA, Ehmann WD, Markesbery WR. Copper, iron, and zinc imbalances in severely degenerated brain regions in Alzheimer's disease: possible relation to oxidative stress. J Neurol Sci 1996, 143: 137-142.

[69] Eskici G, Axelsen PH. Copper and oxidative stress in the pathogenesis of Alzheimer's disease. Biochemistry 2012, 51: 6289-6311.

[70] Jomova K, Vondrakova D, Lawson M, Valko M. Metals, oxidative stress and neurodegenerative disorders. Mol Cell Biochem 2010, 345: 91-104.

[71] Curtain CC, Ali F, Volitakis I, Cherny RA, Norton RS, Beyreuther $\mathrm{K}$, et al. Alzheimer's disease amyloid-beta binds copper and zinc to generate an allosterically ordered membrane-penetrating structure containing superoxide dismutase-like subunits. J Biol Chem 2001, 276: 2046620473.

[72] Opazo C, Huang X, Cherny RA, Moir RD, Roher AE, White AR, et al. Metalloenzyme-like activity of Alzheimer's disease beta-amyloid. Cu-dependent catalytic conversion of dopamine, cholesterol, and biological reducing agents to neurotoxic $\mathrm{H}_{2} \mathrm{O}_{2}$. J Biol Chem 2002, 277: 40302-40308.

[73] Huang X, Cuajungco MP, Atwood CS, Hartshorn MA, Tyndall JD, Hanson GR, et al. Cu(II) potentiation of alzheimer abeta neurotoxicity. Correlation with cell-free hydrogen peroxide production and metal reduction. J Biol Chem 1999, 274: 37111-37116.

[74] Lynch T, Cherny RA, Bush Al. Oxidative processes in Alzheimer's disease: the role of abeta-metal interactions. Exp Gerontol 2000, 35: 445-451.

[75] Altamura S, Muckenthaler MU. Iron toxicity in diseases of aging: Alzheimer's disease, Parkinson's disease and atherosclerosis. J Alzheimers Dis 2009, 16: 879-895.

[76] Pulliam JF, Jennings CD, Kryscio RJ, Davis DG, Wilson $\mathrm{D}$, Montine TJ, et al. Association of HFE mutations with neurodegeneration and oxidative stress in Alzheimer's disease and correlation with APOE. Am J Med Genet B Neuropsychiatr Genet 2003, 119B: 48-53.

[77] Honda K, Casadesus G, Petersen RB, Perry G, Smith MA. Oxidative stress and redox-active iron in Alzheimer's disease. Ann N Y Acad Sci 2004, 1012: 179-182.

[78] Wan L, Nie G, Zhang J, Luo Y, Zhang P, Zhang Z, et al. beta-Amyloid peptide increases levels of iron content and oxidative stress in human cell and Caenorhabditis elegans models of Alzheimer disease. Free Radic Biol Med 2011, 50: 122-129.

[79] Sensi SL, Rapposelli IG, Frazzini V, Mascetra N. Altered oxidant-mediated intraneuronal zinc mobilization in a triple transgenic mouse model of Alzheimer's disease. Exp Gerontol 2008, 43: 488-492.

[80] Sensi SL, Paoletti P, Bush Al, Sekler I. Zinc in the physiology and pathology of the CNS. Nat Rev Neurosci 2009, 10: 780791.

[81] Goedert M, Spillantini MG. A century of Alzheimer's disease. Science 2006, 314: 777-781.

[82] Petersen RB, Nunomura A, Lee HG, Casadesus G, Perry G, Smith MA, et al. Signal transduction cascades associated with oxidative stress in Alzheimer's disease. J Alzheimers Dis 2007, 11: 143-152.

[83] Cente M, Filipcik P, Pevalova M, Novak M. Expression of a truncated tau protein induces oxidative stress in a rodent model of tauopathy. Eur J Neurosci 2006, 24: 1085-1090.

[84] David DC, Hauptmann S, Scherping I, Schuessel K, Keil U, Rizzu $\mathrm{P}$, et al. Proteomic and functional analyses reveal a mitochondrial dysfunction in P301L tau transgenic mice. J Biol Chem 2005, 280: 23802-23814.

[85] Dumont M, Stack C, Elipenahli C, Jainuddin S, Gerges M, Starkova NN, et al. Behavioral deficit, oxidative stress, and mitochondrial dysfunction precede tau pathology in P301S transgenic mice. FASEB J 2011, 25: 4063-4072.

[86] Yoshiyama Y, Higuchi M, Zhang B, Huang SM, Iwata N, Saido TC, et al. Synapse loss and microglial activation precede tangles in a P301S tauopathy mouse model. Neuron 2007, 53: 337-351.

[87] Elipenahli C, Stack C, Jainuddin S, Gerges M, Yang L, Starkov A, et al. Behavioral improvement after chronic administration of coenzyme Q10 in P301S transgenic mice. J Alzheimers Dis 2012, 28: 173-182.

[88] Tuppo EE, Arias HR. The role of inflammation in Alzheimer's disease. Int J Biochem Cell Biol 2005, 37: 289-305.

[89] El Khoury J, Hickman SE, Thomas CA, Cao L, Silverstein SC, Loike JD. Scavenger receptor-mediated adhesion of microglia to beta-amyloid fibrils. Nature 1996, 382: 716-719.

[90] Johnstone M, Gearing AJ, Miller KM. A central role for astrocytes in the inflammatory response to beta-amyloid; chemokines, cytokines and reactive oxygen species are produced. J Neuroimmunol 1999, 93: 182-193.

[91] Smits HA, Rijsmus A, van Loon JH, Wat JW, Verhoef $\mathrm{J}$, Boven LA, et al. Amyloid-beta-induced chemokine production in primary human macrophages and astrocytes. $\mathrm{J}$ Neuroimmunol 2002, 127: 160-168.

[92] Luo Y, Sunderland T, Roth GS, Wolozin B. Physiological levels of beta-amyloid peptide promote PC12 cell proliferation. Neurosci Lett 1996, 217: 125-128. 
[93] Kontush A, Schekatolina S. Vitamin E in Neurodegenerative Disorders: Alzheimer's Disease. Ann N Y Acad Sci 2004, 1031: 249-262.

[94] Puzzo D, Privitera L, Leznik E, Fa M, Staniszewski A, Palmeri A, et al. Picomolar amyloid-beta positively modulates synaptic plasticity and memory in hippocampus. J Neurosci 2008, 28: 14537-14545.

[95] Nunomura A, Perry G, Aliev G, Hirai K, Takeda A, Balraj EK, et al. Oxidative damage is the earliest event in Alzheimer disease. J Neuropathol Exp Neurol 2001, 60: 759-767.

[96] Nunomura A, Tamaoki T, Tanaka K, Motohashi N, Nakamura $\mathrm{M}$, Hayashi $\mathrm{T}$, et al. Intraneuronal amyloid beta accumulation and oxidative damage to nucleic acids in Alzheimer disease. Neurobiol Dis 2010, 37: 731-737.

[97] Castegna A, Aksenov M, Aksenova M, Thongboonkerd V, Klein JB, Pierce WM, et al. Proteomic identification of oxidatively modified proteins in Alzheimer's disease brain. Part I: creatine kinase BB, glutamine synthase, and ubiquitin carboxy-terminal hydrolase L-1. Free Radic Biol Med 2002, 33: 562-571.

[98] Paola D, Domenicotti C, Nitti M, Vitali A, Borghi R, Cottalasso $D$, et al. Oxidative stress induces increase in intracellular amyloid beta-protein production and selective activation of betal and betall PKCs in NT2 cells. Biochem Biophys Res Commun 2000, 268: 642-646.

[99] Nunomura A, Perry G, Pappolla MA, Friedland RP, Hirai K, Chiba $\mathrm{S}$, et al. Neuronal oxidative stress precedes amyloidbeta deposition in Down syndrome. J Neuropathol Exp Neurol 2000, 59: 1011-1017.

[100] Oda A, Tamaoka A, Araki W. Oxidative stress up-regulates presenilin 1 in lipid rafts in neuronal cells. J Neurosci Res 2010, 88: 1137-1145.

[101] Tamagno E, Bardini P, Obbili A, Vitali A, Borghi R, Zaccheo $D$, et al. Oxidative stress increases expression and activity of BACE in NT2 neurons. Neurobiol Dis 2002, 10: 279-288.

[102] Yoo MH, Gu X, Xu XM, Kim JY, Carlson BA, Patterson AD, et al. Delineating the role of glutathione peroxidase 4 in protecting cells against lipid hydroperoxide damage and in Alzheimer's disease. Antioxid Redox Signal 2010, 12: 819827.

[103] Tamagno E, Guglielmotto M, Aragno M, Borghi R, Autelli $\mathrm{R}$, Giliberto $\mathrm{L}$, et al. Oxidative stress activates a positive feedback between the $\gamma$ - and $\beta$-secretase cleavages of the $\beta$-amyloid precursor protein. J Neurochem 2008, 104: 683695.

[104] Cole GM, Teter B, Frautschy SA. Neuroprotective effects of curcumin. Adv Exp Med Biol 2007, 595: 197-212.

[105] Mandel SA, Amit T, Kalfon L, Reznichenko L, Youdim MB. Targeting multiple neurodegenerative diseases etiologies with multimodal-acting green tea catechins. J Nutr 2008, 138:
1578S-1583S.

[106] Smith JV, Luo Y. Studies on molecular mechanisms of Ginkgo biloba extract. Appl Microbiol Biotechnol 2004, 64: 465-472.

[107] Dumont M, Wille E, Stack C, Calingasan NY, Beal MF, Lin MT. Reduction of oxidative stress, amyloid deposition, and memory deficit by manganese superoxide dismutase overexpression in a transgenic mouse model of Alzheimer's disease. FASEB J 2009, 23: 2459-2466.

[108] Murakami K, Murata N, Noda Y, Tahara S, Kaneko T, Kinoshita N, et al. SOD1 (copper/zinc superoxide dismutase) deficiency drives amyloid beta protein oligomerization and memory loss in mouse model of Alzheimer disease. J Biol Chem 2011, 286: 44557-44568.

[109] Gamblin TC, King ME, Kuret J, Berry RW, Binder LI. Oxidative regulation of fatty acid-induced tau polymerization. Biochemistry 2000, 39: 14203-14210.

[110] Schweers O, Mandelkow EM, Biernat J, Mandelkow E. Oxidation of cysteine-322 in the repeat domain of microtubule-associated protein tau controls the in vitro assembly of paired helical filaments. Proc Natl Acad Sci U S A 1995, 92: 8463-8467.

[111] Melov S, Adlard PA, Morten K, Johnson F, Golden TR, Hinerfeld D, et al. Mitochondrial oxidative stress causes hyperphosphorylation of tau. PLoS One 2007, 2: e536.

[112] Goedert M, Hasegawa M, Jakes R, Lawler S, Cuenda A, Cohen P. Phosphorylation of microtubule-associated protein tau by stress-activated protein kinases. FEBS Lett 1997, 409: 57-62.

[113] Wadsworth TL, Bishop JA, Pappu AS, Woltjer RL, Quinn JF. Evaluation of coenzyme $Q$ as an antioxidant strategy for Alzheimer's disease. J Alzheimer Dis 2008, 14: 225-234.

[114] Yang X, Dai G, Li G, Yang E. Coenzyme Q10 reduces $\beta$-amyloid plaque in an APP/PS1 transgenic mouse model of Alzheimer's disease. J Mol Neurosci 2010, 41: 110-113.

[115] Yang X, Yang Y, Li G, Wang J, Yang E. Coenzyme Q10 attenuates $\beta$-amyloid pathology in the aged transgenic mice with Alzheimer Presenilin 1 mutation. J Mol Neurosci 2008, 34: 165-171.

[116] Gutzmann H, Kuhl KP, Hadler D, Rapp MA. Safety and efficacy of idebenone versus tacrine in patients with Alzheimer's disease: results of a randomized, double-blind, parallel-group multicenter study. Pharmacopsychiatry 2002, 35: 12-18.

[117] Senin U, Parnetti L, Barbagallo-Sangiorgi G, Bartorelli L, Bocola V, Capurso A, et al. Idebenone in senile dementia of Alzheimer type: a multicentre study. Arch Gerontol Geriatr 1992, 15: 249-260.

[118] Thal LJ, Grundman M, Berg J, Ernstrom K, Margolin R, Pfeiffer $\mathrm{E}$, et al. Idebenone treatment fails to slow cognitive decline in Alzheimer's disease. Neurology 2003, 61: 1498-1502. 
[119] Smith RAJ, Murphy MP. Animal and human studies with the mitochondria-targeted antioxidant MitoQ. Ann N Y Acad Sci 2010, 1201: 96-103.

[120] Okun I, Tkachenko SE, Khvat A, Mitkin O, Kazey V, Ivachtchenko AV. From anti-allergic to anti-Alzheimer's: molecular pharmacology of Dimebon. Curr Alzheimer Res 2010, 7: 97-112.

[121] Doody RS, Gavrilova SI, Sano M, Thomas RG, Aisen PS, Bachurin SO, et al. Effect of dimebon on cognition, activities of daily living, behaviour, and global function in patients with mild-to-moderate Alzheimer's disease: a randomised, doubleblind, placebo-controlled study. Lancet 2008, 372: 207-215.

[122] Jones RW. Dimebon disappointment. Alzheimers Res Ther 2010, 2: 25.

[123] Baum L, Lam CW, Cheung SK, Kwok T, Lui V, Tsoh J, et al. Six-month randomized, placebo-controlled, double-blind, pilot clinical trial of curcumin in patients with Alzheimer disease. J Clin Psychopharmacol 2008, 28: 110-113.

[124] Pettegrew JW, Klunk WE, Panchalingam K, Kanfer JN, McClure RJ. Clinical and neurochemical effects of acetyl-Lcarnitine in Alzheimer's disease. Neurobiol Aging 1995, 16 : $1-4$.

[125] Thal LJ, Carta A, Clarke WR, Ferris SH, Friedland RP,
Petersen RC, et al. A 1-year multicenter placebo-controlled study of acetyl-L-carnitine in patients with Alzheimer's disease. Neurology 1996, 47: 705-711.

[126] Thal LJ, Calvani M, Amato A, Carta A, Group ftA-I-CS. A 1 -year controlled trial of acetyl-I-carnitine in early-onset $A D$. Neurology 2000, 55: 805-810.

[127] Sano M, Ernesto C, Thomas RG, Klauber MR, Schafer K, Grundman M, et al. A Controlled Trial of selegiline, alphatocopherol, or both as treatment for Alzheimer's disease. $\mathrm{N}$ Engl J Med1997, 336: 1216-1222.

[128] Abramova NA, Cassarino DS, Khan SM, Painter TW, Bennett JP. Inhibition by $\mathrm{R}(+)$ or $\mathrm{S}(-)$ pramipexole of caspase activation and cell death induced by methylpyridinium ion or beta amyloid peptide in SH-SY5Y neuroblastoma. J Neurosci Res 2002, 67: 494-500.

[129] Manczak M, Mao P, Calkins MJ, Cornea A, Reddy AP, Murphy MP, et al. Mitochondria-targeted antioxidants protect against amyloid- $\beta$ toxicity in Alzheimer's disease neurons. J Alzheimer Dis 2010, 20: 609-631.

[130] Chen Z, Zhong C. Decoding Alzheimer's disease from perturbed cerebral glucose metabolism: implications for diagnostic and therapeutic strategies. Prog Neurobiol 2013, 108: 21-43. 